\title{
Rethinking the Paradigm for Child Protection
}

\author{
Jane Waldfogel
}

Jane Waldfogel, Ph.D., is an assistant professor of social work and public affairs at Columbia University, New York, NY.

\begin{abstract}
Mounting pressures on the nation's system for helping children who are abused and neglected have prompted new efforts to reform the child protective services (CPS) system to better protect children's safety. As this article explains, current reform efforts are focusing on the "front end" of the system, in which reports of abuse and neglect are screened and investigated, and caseworkers recommend whether and when to close a case, provide in-home services, or remove a child from a home. This article discusses the problems of the CPS system that are currently receiving attention, and it closely examines one proposal for reform-the community-based partnership for child protection. This approach emphasizes targeting investigations by CPS toward only high-risk families, building collaborative community networks that can serve lower-risk families, and providing a differentiated response to both high- and low-risk families that is tailored to each family's situation. Early experiences implementing these ideas in Missouri, Florida, and Iowa illustrate the promise and challenges of reform.
\end{abstract}

$\mathrm{T}$

he child protective services (CPS) system is a relatively young arm of government, initiated in the 1960s and 1970s to receive and investigate reports of child abuse and neglect. The system has grown rapidly: In 1967, fewer than 10,000 reports of abuse and neglect were made to child protective services, ${ }^{1}$ but by the mid-1990s, more than 3 million reports were being made each year.,2,3

Although CPS has been vested with a great deal of authority to carry out its protective mandate, its ability to protect children from abuse or neglect at the hands of their parents is limited. No one can judge with perfect foresight which children are at genuine risk of abuse or neglect. Moreover, as more and more reports of children at risk pour into the system, the system's capacity to respond effectively to the reports it receives has been strained. At the same time, because other parts of the child and family services system have been cut back, referrals to CPS have increasingly been used to obtain needed services for families, even if those families do not need the scrutiny that CPS provides.

The wide range of cases flooding the CPS system, and the problems the authoritative system has in responding to the varied needs of families, 
together set the context for current efforts to rethink CPS. This article examines how reports, investigations, and services are currently handled in CPS. It then reviews several proposals for reforming the CPS system, and it describes one proposal in detail: a community-based partnership for child protection. Three main themes characterize this proposal: CPS should target its investigative efforts more appropriately, CPS should collaborate with partners in the community to provide more supportive services to both high-risk and low-risk families, and CPS and its community partners should provide a more customized response to families at risk of abuse or neglect. Descriptions of three state reform initiatives illustrate these ideas and reveal some of the challenges that arise in implementing CPS reform.

\section{The Mandate and Capacity of Child Protective Services (CPS)}

CPS refers to a highly specialized set of laws, funding mechanisms, and agencies that together constitute the government's response to reports of child abuse and neglect. (See also the article by Schene in this journal issue.) The fact that responsibility for child protective services rests in a public agency is not accidental. CPS is vested with public authority: the power to investigate reports of abuse and neglect, the power to remove children from their homes, and the power to petition a court for custody. CPS is an authoritative agency-for the most part, families do not come to the agency voluntarily and cannot terminate their involvement with the agency at will. The authoritative character of the system colors its public image and has implications for oversight and accountability. Society has a stake in ensuring that CPS exercises its authority responsibly and fairly, providing adequate protection for children without unduly interfering with families' rights to raise their children free of unwarranted government intervention.

The ability of CPS to conduct thorough investigations and to assist families depends on funding and staff resources. CPS agen- cies receive federal, state, and a small amount of local funding. The federal dollars primarily pay for the costs of foster care and other out-of-home placements, while the state dollars fund the bulk of staff costs. (The article by Courtney in this journal issue discusses federal funding streams.) CPS agencies are staffed by caseworkers with varying qualifications, ranging from entry level staff who might not have college degrees to senior clinicians with master's degrees in social work or related fields. Often a family will be assigned one caseworker for their investigation, a different one for their assessment and ongoing service provision, and yet another if the child goes into foster care. Most states contract with private nonprofit and for-profit agencies to provide placement services such as foster care, residential treatment, or adoption, as well as supportive services to families such as child care, homemaking assistance, or respite care.

CPS expends many of its resources at the front end of the system, where reports to hot lines are received and screened, and those that meet threshold criteria are assigned for investigation. There has been an enormous increase in reports of abuse and neglect over the past few decades. Reporting rates have risen from 4 per 1,000 children in 1975 to 31 per 1,000 in 1985 and 47 per 1,000 in $1994 .^{3}$ This dramatic rise likely reflects both a 
true increase in child maltreatment and increased awareness on the part of professionals and the community at large about what constitutes reportable abuse and neglect. Whatever their source, the swelling numbers of reports have overwhelmed CPS agencies, and all agencies have in place procedures to prioritize among them. (The article by English in this journal issue discusses reports and risk assessment.)

The prioritizing of CPS reports begins at the point of screening. Nationwide, CPS hot lines screen out about half of the reports they receive. ${ }^{2}$ The remainder are assigned to a caseworker for investigation. The primary purpose of the investigation is to establish the safety of the child victim and the identity of the adult perpetrator. The family's need for services may also be assessed, but this is secondary to the main purpose of the investigation. From the perspective of the family, the

More than $70 \%$ of reported cases are closed by the end of the investigation because the report was screened out by the hot line or the investigator recommended closing the case.

investigation is an intrusive and adversarial process. At the first contact, the investigator informs the family of the allegations and may warn them that anything they say can be used against them if the case is taken to court. At the end of the investigation, the caseworker decides whether the allegations in the report are substantiated and what steps are necessary to protect the child from further harm.

As Figure 1 shows, more than $70 \%$ of all reported cases nationwide are closed by the end of the investigation, either because the report was screened out by the hot line worker (approximately 50\% of reported cases) or because the investigator recommended closing the case (about 20\% of reported cases). ${ }^{2}$ The investigator will recommend that a case be closed if the evidence of abuse or neglect is insufficient to remove the child or to compel the family to participate in in-home services involuntarily, or if a family is considered low-risk and hence a lower priority for services than other cases. In making these decisions, then, CPS takes into account not only the child's need for protec- tion and the family's need for services but also, implicitly, the services available.

The remaining cases, about $30 \%$ of those originally reported to CPS, stay open for a period of time so the caseworker can assess the family and develop a plan for services. Service plans typically call for "ongoing treatment" or "protective oversight" (intermittent calls or visits by a caseworker), and may include other services such as family counseling or day care for a preschool-age child. In about one-third of these cases-less than $10 \%$ of those originally reported to CPSthe risk of severe maltreatment is so high that the case is taken to court, which may assign custody of the children to the state, authorize the removal of the children and their placement into substitute care, or terminate parental rights altogether. ${ }^{3}$ (The article by Schene in this journal issue discusses these steps in more detail.)

This brief description of the current CPS system highlights the fact that CPS is primarily an investigative system designed to intervene authoritatively with families whose children are at risk of serious abuse or neglect. These families, however, constitute only a small share of the families referred to CPS. Seven of ten cases are not investigated at all or are closed after the investigation. For this latter group of families, one has to wonder how effective and helpful CPS has been. In spite of having been referred to CPS and, in some cases, having undergone a coercive and intrusive investigation, none of these families end up receiving ongoing services.

\section{What Is Wrong with CPS Today?}

Over the past decade, many working within child protection and child welfare-and many clients, advocates, and scholars-have raised concerns about CPS. ${ }^{4}$ Associations of public agency administrators, attorneys, policy analysts, scholars, and blue-ribbon government panels have produced recommendations to overhaul the reporting and investigation of child abuse and neglect. ${ }^{5-10}$ The most recent of these panels was a task force called the Harvard Executive Session, which brought together child welfare administrators, practitioners, policymakers, and experts between 1994 and 1997. This 
Figure 1

\section{What Happens to Reports of Possible Maltreatment Once They Are Received by Child Protective Services}

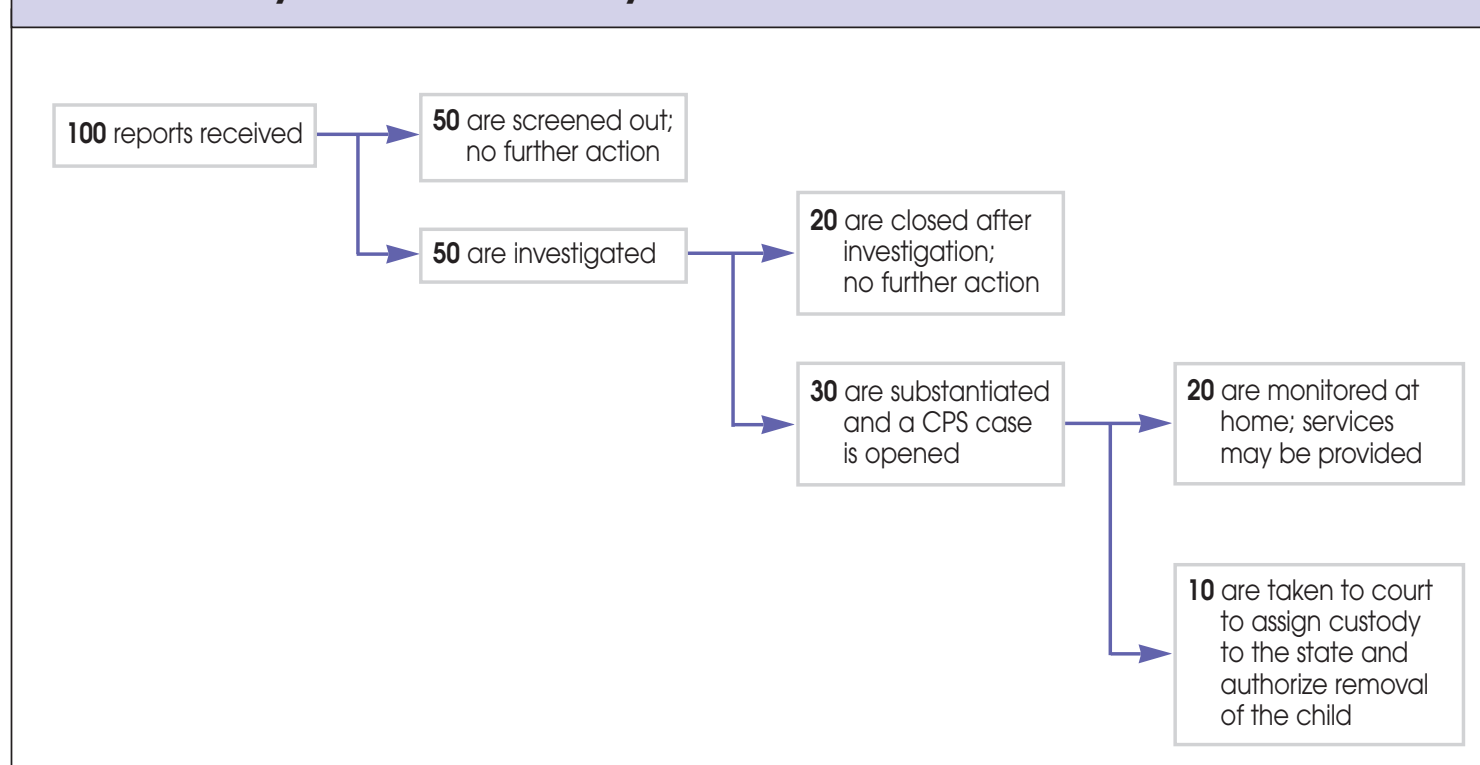

Sources: Author estimates from data in Wiese, D., and Daro, D. Current trends in child abuse reporting and fatalities: The results of the 1994 annual fifty-state survey. Working paper no. 808. Chicago: National Committee to Prevent Child Abuse, 1995; and U.S. Department of Health and Human Services, National Center on Child Abuse and Neglect. Child maltreatment, 1993: Reports from the states to the national child abuse and neglect data system. Washington, DC: U.S. Government Printing Office, 1995.

article draws on the work of that group. ${ }^{11}$ Five major criticisms of the CPS system framed the reform ideas proposed by the Executive Session. (See Box 1.) $)^{3}$ Each concern is discussed below.

\section{Overinclusion}

For a variety of reasons, some families are unjustly or inappropriately reported to CPS, exposing them unnecessarily to coercive and intrusive investigations. That problem can be termed "overinclusion." For instance, according to parents' rights groups, the current abuse and neglect statutes and practices lead CPS to intervene in the disciplinary decisions of some families that do not warrant public intervention; in addition, both parents and CPS agencies worry that individuals may file baseless, vindictive reports as part of ongoing custody disputes, fights with neighbors, and so on. ${ }^{4}$ Child protection professionals also express concerns about the disproportionate representation of children from poor and minority families in the CPS system. These families may be at higher risk for conditions of poverty-related neglect, such as inadequate housing or child care, and they also may be more likely to come to the attention of reporters.
Contributing to the problem of overinclusion is the perception on the part of some community advocates that families stand a better chance of getting services such as child care or therapy if they are identified as CPS cases. ${ }^{7}$ This perception leads some to refer low-risk families to CPS, even though that referral is no guarantee of receiving any services at all. Together with false reports of abuse and neglect, reports concerning relatively low-risk families unnecessarily add to the volume of cases flooding the CPS system. These inappropriately referred cases are problematic not only because of the potential harm to the families involved, but also because they may impede the ability of the system to respond effectively to other, higher-risk cases.

\section{Capacity}

The second problem, then, has to do with capacity. Put simply, the number of families involved with the child protection system far exceeds the capacity of the system to serve them responsibly. Both federal mandates and state laws require that CPS agencies accept and respond to reports of child abuse, yet the resources devoted to this activity have not kept pace with the rapidly rising 


\section{Box 1}

\section{Concerns Regarding the Current Child Protective Services (CPS) System Identified by the Harvard Executive Session}

- Overinclusion: Some families are referred to CPS who should not be.

- Capacity: The number of families referred to the system exceeds the system's ability to respond effectively.

- Underinclusion: Some families who should be referred to CPS are not.

- Service Orientation: The authoritative approach of CPS is not appropriate for many of the families referred to it.

- Service Delivery: Many families do not receive the services they need.

Source: Waldfogel, J. The future of child protection. Cambridge, MA: Harvard University Press, Fall 1998.

demand. As a result, even the systems with the best resources have been unable to keep up with the increased caseloads. There is consensus that the system is at or near the breaking point. ${ }^{12}$

\section{Underinclusion}

The third problem, paradoxically, is underinclusion. Some children and families who could benefit from child protective services are not reached, or are not reached adequately, by CPS agencies. Even the best reporting and screening systems will miss some abusive families who should be subject to child protective intervention-a problem that is tragically highlighted each time a child who was known to authorities dies from abuse or neglect. Although the media reports of these tragic cases often provide a distorted picture of children in need of protection, they do highlight the fact that the system misses some very highrisk cases.

Moreover, child welfare professionals and community advocates point out that another group is underincluded: low-risk families who voluntarily contact CPS to ask for help, only to have their requests denied because they are not high-risk. Given the limited availability of preventive services such as child care or family therapy, excluding these families from CPS all too often means that they will not receive help until they cross the line into abuse and neglect. At that point, their problems may be more intractable, and more damage will have been done to the child.

\section{Service Orientation}

The fourth and fifth problems have to do with services for families. The basic service orientation of the child protection system has long been twofold: to investigate and remedy abuse and neglect in an authoritative way, and to keep families together whenever possible. Reflecting the tension between these competing goals, CPS agencies have tended to alternately emphasize child rescue (by promptly removing the child from home to a safer setting) or family preservation (by keeping the child at home and providing services to strengthen the family). (See the articles by Schene and by McCroskey and Meezan in this journal issue.) Yet neither orientation is correct for all families, and as CPS follows swings of the pendulum from one approach to the other, some families are ill-served.

\section{Service Delivery}

A cluster of issues concerning the availability of services and the fit between services and family needs also poses problems for CPS agencies. In many instances, needed services simply are not available. Service delivery tends to be uneven across communities, with particular shortages of services delivered in languages other than English. An overarching service delivery issue is that families often have multiple and overlapping problems, while services for them tend to be fragmented, delivered in separate locations by different professionals. ${ }^{13}$ Although this issue is not unique to child protection, the lack of service integration is particularly problematic for CPS. Many 
families need services, such as substanceabuse treatment, housing, or child care, that the agency does not provide directly and must obtain through the cooperation of other service providers. CPS caseworkers typically cannot access funds to buy services on a case-by-case basis.

Another fundamental service delivery problem is posed by the basic casework provided by CPS, which in many cases is the primary service families receive from CPS. Because they are large public bureaucracies engaged in a high-stakes enterprise, CPS agencies tend to adopt a uniform approach to all cases, prescribing specific procedures that must be followed in each case rather than encouraging a customized approach that takes into account the fact that families coming to the attention of CPS are a varied group whose needs change over time. Although standardized procedures exist to ensure that the delivery of services is fair, responsible, and equitable, they often mean that families do not get a response that is sufficiently tailored to their needs.

These problems pose a tremendous challenge for CPS reformers. It is clear that the system would protect children more effectively if fewer families were referred to CPS, and some families would be better off if they could be served in a less adversarial way by someone other than CPS. At the same time, however, the system already misses some very serious cases, and most communities face a shortfall of services. Nor can CPS meet families' needs on its own. For that reason, a more effective response to families requires closer collaboration between CPS and other service providers in the community.

\section{Recent Reform Proposals}

The problems facing CPS have led a number of individuals and groups to rethink child protection in recent years. One stream of reform proposals focuses on the concerns about overinclusion, capacity, and service orientation, and suggests that the mandate of CPS should be more narrowly defined and more vigorously pursued. A second reform stream emphasizes the additional need to broaden access to services that protect children and strengthen families, and recommends building partnerships between CPS agencies and a variety of community partners as a way of remedying the problems related to underinclusion and service delivery.

\section{Proposals to Narrow CPS}

Some of those who call for narrowing the range of families investigated by CPS recommend specific reforms, such as establishing tighter guidelines for reporters of child abuse and neglect and stricter criteria for CPS staff who screen reports. ${ }^{14}$ The intent of these proposals is to reduce the number of families inappropriately referred to CPS, thereby sparing lower-risk families unnecessary intervention and freeing scarce CPS resources for higher-risk families. For

\section{CPS agencies tend to prescribe specific procedures that must be followed in each case rather than encouraging a customized approach that takes into account the differing needs of families.}

instance, some reformers would limit CPS intervention to cases in which a criminal act has been perpetrated against a child and would locate CPS in the criminal justice system, rather than the social services arena. Presumably, this shift would resolve the tension between the CPS agency's investigative and helping roles, and would allow social workers to focus their attention on cases of noncriminal maltreatment. ${ }^{15}$ However, these narrowing proposals tend to be fairly silent on the question of how the cases excluded from CPS would be served, and how services for them would be authorized and funded.

A second group of narrowing proposals calls for the mandate of CPS to be narrowed and for more services to be provided to families outside CPS. Several of these "narrowing plus" proposals conceptualize a three-tiered system, with a more narrowly focused CPS, an expanded voluntary family support system, and an adequately funded child well-being system (for cash assistance, education, health care, and so on).$^{8,16,17}$ Another approach would create overarching Children's Authorities to provide both the authoritative CPS response to highrisk families and the supportive non-CPS response to lower-risk families. ${ }^{18}$ 
Most of those who propose narrowing CPS take for granted the existence and capacity of a non-CPS service system to meet the needs of lower-risk families. What is left unclear, however, is how that new and vigorous child and family services system would come into being, and what the source of its political mandate and funding would be. This is an important issue because if the scope of CPS is narrowed and more cases are excluded, and if no alternative service system is in place, vulnerable children and families might receive even less assistance than they do today. And, since the ability of the system to sort cases by level of risk is imperfect, some vulnerable families left unserved could in fact be cases at high risk of abuse or neglect.

The difficulty of sorting cases by level of risk is a challenge for all narrowing proposals. Despite advances in risk assessment, it is not possible to calculate the risk of abuse or neglect with certainty, and so the process of sorting cases into or out of CPS is fraught with danger. (See the article by English in this journal issue.) Tightening definitions of abuse and neglect for reporters and screeners may help to focus CPS efforts, but new definitions will not suffice to bring about accurate and safe sorting of cases into those that warrant authoritative intervention and those that do not. Moreover, the sorting process must take into account the fact that families are not always as they first appear, and their situations change over time. As a result, some cases will be placed in the wrong group and either receive inappropriate services or need to be reassigned. Simply dividing cases into two groups also begs the question of how the system should respond to the range of families within each group, who are not all alike. Thus, rethinking CPS also means considering ways to move beyond the standardized, one-size-fitsall response to families that CPS currently provides.

This analysis suggests that efforts to narrow the role of CPS can best be viewed as part of a larger and more complex strategy to improve child protection. The working group assembled for the Harvard Executive Session took on the challenge of conceptualizing that larger strategy. ${ }^{19}$ The new paradigm proposed by this group emphasizes narrowing the focus of CPS, building community capacity and partnerships to respond to both low-risk and high-risk families, and providing a more customized or "differential" response to families' needs. ${ }^{3,20}$ An overview of that proposal is provided below, along with illustrations of early efforts to implement aspects of the overall strategy in Missouri, Florida, and Iowa.

\section{A New Paradigm for Child Protection}

The new paradigm proposed by the Executive Session is a partnership model in which the public CPS agency shares responsibility for child protection with a wide range of partners in the community to provide a more differentiated response to children at 
risk of abuse or neglect. ${ }^{3,20}$ This new paradigm sees reform proceeding along two tracks: one track is to improve the capacity of CPS to respond effectively to the high-risk cases that need authoritative intervention; the other track is to enhance the capacity of community partners to provide services to help protect children in both high- and lowrisk families.

At the end point of the reforms, it is envisioned that CPS, in partnership with the criminal justice system and other agencies, will respond more effectively to protect children in the highest-risk cases of abuse or neglect. The responsibility for responding to children and families who are at lower risk (and hence do not need an authoritative intervention) will increasingly shift from CPS to other public or private agencies in the community. The various partners in the child protection system will work together in a coordinated way at the community level, perhaps even establishing local governance entities to oversee the planning, funding, and delivery of child protective services.

Shifting to the new paradigm would represent a dramatic change from current practice in several respects. One, in line with earlier proposals, it would narrow the reach of the authoritative CPS system and target that intervention for the children most at risk. This would help ensure that the system acts aggressively to protect children at high risk, while not intervening too coercively with families at lower risk. Two, consistent with the idea of "narrowing plus," it would establish a less adversarial and more helpful response to families who are at risk of abuse or neglect but for whom coercive intervention is not necessary. Families at lower risk would be able to access services on a voluntary basis from a broad array of community agencies. Three, the new paradigm would move beyond narrowing proposals by pulling together public and private agencies, along with families and community members, to better protect children from the threat of abuse or neglect. Working as a team, CPS and its partners would provide each family with a response tailored to the family's unique set of problems, needs, and resources.

How would the operations of a community-based partnership for child protection differ from the way CPS works today? Three differences are key.

\section{Cross-Agency Service Planning}

If caseworkers are to provide a customized response to the range of problems that can place children at risk of abuse and neglect, they will need easier access to resources held by other agencies. For example, to combat the problems presented by alcohol and drug use, front-line staff from CPS and partner

\section{At the end point of the reforms, it is envisioned that CPS, in partnership with the criminal justice system and other agencies, will respond more effectively to protect children in the highest-risk cases of abuse or neglect.}

agencies will have to be able to reliably access substance-abuse treatment for parents. ${ }^{21}$ To accomplish this, they could commit resources to expanding treatment capacity in their communities, or work out agreements giving priority access to cases with children at risk of abuse or neglect. Interagency teams can also encourage the sharing of resources across agencies. In addition, caseworkers will need flexible funds that can be used to purchase services or goods that are not held by a partner agency.

\section{Links with Informal Helpers}

The new paradigm also emphasizes a larger role for informal helpers. Previous approaches to child protection have tended to discourage reliance on informal sources of support for families. Since parents who are abusing or neglecting their children may themselves be the products of abusive or neglectful families, extended family members are not always considered good candidates to provide help in protecting children. Moreover, the impoverished neighborhoods where many children at risk of abuse or neglect live may offer few social supports or natural helpers. ${ }^{22}$ In the proposed communitybased partnership for child protection, the potential importance of informal support from family or community members in preventing child abuse and neglect is taken seriously but is not seen as a panacea. Rather, 
the role played by informal supports would vary case by case, depending on an assessment of the family's needs and the resources available to meet those needs. ${ }^{23}$

\section{Differential Response}

A third important characteristic of the new paradigm is its emphasis on providing a differential response, in which CPS and its partners tailor their approach and services to fit each family's problems, needs, and resources. At the most general level, a differential response implies there are at least two pathways for families referred for abuse or

\section{In Missouri and Florida, CPS agencies limit authoritative investigations to the most serious cases of suspected abuse or neglect, and provide assessment- and service-oriented responses to other families.}

neglect: a mandatory investigation for highrisk families, and an assessment- and serviceoriented response for low-risk families. Within each pathway, the approach of the caseworkers and the services they recommend will be customized to fit the family's situation. Caseworkers will constantly reevaluate family needs and re-tailor their service plans accordingly, drawing on a wide array of resources to support families and help protect children.

\section{State Efforts to Implement Reform: Three Case Studies}

In several states and localities, CPS agencies are implementing elements of this reform vision. The experiences of three such states-Missouri, Florida, and Iowa-illustrate the progress that can be made. In Missouri and Florida, CPS agencies are implementing a differential response at the point of entry to CPS: they limit authoritative investigations to the most serious cases of suspected abuse or neglect, and provide assessment- and service-oriented responses to the other families referred for child protective concerns. In Florida and Iowa, CPS agencies are building partnerships in the community to provide better-coordinated services and more fully differentiated responses to families. Florida is also experi- menting with ways to involve informal helpers as partners in child protection.

\section{Missouri: A Differential Response}

In 1994, Missouri's state assembly passed legislation to allow the Division of Family Services to establish two different responses to reports of child abuse and neglect: a mandatory investigation for high-risk cases and a voluntary assessment for lower-risk cases. ${ }^{24}$ The impetus for the bill was a consensus on the part of liberal and conservative legislators that the CPS agency was intervening too aggressively in families who might have been served on a voluntary basis, and that the system was not intervening effectively enough to protect children in the most serious cases because it was overwhelmed with nonserious cases and was treating serious and nonserious cases alike.

To respond to these problems, the assembly passed a reform bill authorizing the Division of Family Services to pilot-test a dual-response system in five locations. Recognizing that "families coming to the attention of the Division of Family Services have different intervention needs and require flexible responses from the division and the community in order to protect children and meet the needs of the family," 25 the legislation delineated two responses that CPS would provide. In cases where it was likely that a crime had been committed, or that an alleged perpetrator or a child would have to be removed from the home, the response would take the form of a mandatory investigation by CPS, in cooperation with law enforcement. For all other families, a new nonauthoritative Family Assessment and Service Delivery response would be provided.

These responses differ in several ways. Only the investigation is mandatory. A family referred for assessment may refuse it, whereas a family that refuses an investigation may be brought to court. The investigation is adversarial; it gathers evidence about the alleged abuse or neglect and the alleged perpetrator, and it always includes a referral to law enforcement. The assessment identifies family needs and strengths, and provides services as necessary to lower the risk of abuse or neglect. As a result, specific practices differ. In investigations, for instance, 
concerns about child safety are salient, and investigators must see the child within 24 hours, with or without the parents' consent. An assessment treats parents as partners from the start, so an assessment worker does not see a child before speaking with the parents, as long as there are other means of confirming that the child is all right (for example, by talking with a teacher).

The outcomes of investigation and assessment responses often differ, as well. Investigated cases, if maltreatment is substantiated, continue to be handled in an authoritative manner; these very serious cases are often brought to court. Cases that are assessed, on the other hand, typically continue to be handled in a supportive manner with voluntary services. The emphasis in assessment cases is on prompt and supportive intervention to help resolve family crises so the case can be closed as quickly as possible. Investigated cases are more likely to remain open for extended CPS involvement, whether the child is placed in substitute care or remains at home under CPS supervision. Finally, only investigations can cause a perpetrator's name to be listed on the state's Central Registry. ${ }^{26}$ Thus, families receiving an assessment response need not fear that their involvement with CPS will affect their future employment prospects or brand them as child abusers.

To implement Missouri's reforms, the pilot offices identified local staff to screen reports of maltreatment and assign them for assessment or investigation. (Previously, the statewide hot line staff screened calls to determine which should be investigated.) The reform project developed a training curriculum and new screening forms to emphasize that cases should be assigned to the new assessment response unless a compelling reason existed to do an investigation. Such reasons included allegations of potentially criminal abuse or indications that a child would need to be removed. Since 1994, across the five reform sites, $80 \%$ of the cases have been referred to the assessment track and only $20 \%$ to the investigation track.

Pilot offices have also changed their case assignment procedures. Whenever possible, the assessment worker continues as the family's ongoing caseworker, rather than moving the case to a new worker after the initial response, as is the procedure with investigations. The assessment worker can therefore identify the need for services and authorize services, rather than having one worker assess needs while another puts together a service plan to meet those needs.

It is too soon to tell what the long-run effects of these reforms will be for the families referred to CPS in Missouri. The data collected thus far suggest that the screening decisions are not perfect-some families referred for an assessment have to be switched to the investigative track, and vice

\section{Since 1994, across the five Missouri reform sites, $80 \%$ of the cases have been referred to the assessment track and only $20 \%$ to the investigation track.}

versa. This was to be expected, however, since family needs emerge and change over time. More data are needed to determine whether the primary goals of the reforms are being met-that is, whether children are being better protected and families are being approached in a more helpful way.

\section{Florida: Differential Response and Community Partnerships}

The aims of the differential response reforms in Florida, as in Missouri, are to intervene more effectively with the most serious cases and to intervene in a more helpful manner with less serious cases.27,28 In Florida, the CPS agency has also sought to build better working relationships with communities and parents.

The context for Florida's current reforms was shaped by the passage, in 1992, of legislation pressing the Department of Child and Family Services to decentralize its services and to forge closer community ties. For instance, the legislation created smaller local districts (the unit of government that administers social services in Florida) and required those districts to create local advisory boards. The department was directed to develop a strategic plan to increase the role of communities in child protective services and to improve its relationship with the 
families it served. It was against this backdrop that Florida passed "dual-response" legislation in 1993.

Under Florida's dual-response reform, serious cases of physical abuse or neglect and cases of sexual abuse were investigated, as in the past, and if substantiated they were reported to the Central Registry. Cases deemed to be less serious at the time of screening received a new assessment instead, and they were not listed on the Central Registry. (Florida's reform served as the prototype for Missouri's reform, described above.)

Florida's reform also gave new discretion over CPS cases to local offices and staff. Local offices were to decide which types of cases to handle as investigations or as assessments, and to collaborate with their local planning boards in deciding which services

\section{If CPS shares responsibility for child protection with community partners, does it also share accountability when things go wrong?}

to purchase for families and children. Caseworkers, in collaboration with families, were given more discretion in their handling of cases assigned to the assessment track. The agency has taken steps to strengthen the capacity of its staff to play this expanded role, seeking to increase training, create new job classifications at higher pay scales, and forge closer links to schools of social work.

In 1995, Florida's reformers succeeded in eliminating the use of the Central Registry for employment screening, removing a key reason for drawing a sharp distinction between investigations and assessments (only investigations could result in a listing on the registry). The 1995 legislation also strengthened the expectation for law enforcement involvement in investigations. This meant that, even in serious cases, CPS caseworkers could focus on assessing the children's safety and the family's needs, while the police gathered evidence regarding the incident and perpetrator. With these legislative changes, the CPS agency moved toward an assessment- and service- oriented response for all families reported for abuse and neglect; this allows caseworkers to work with families on a customized, case-by-case basis.

Florida has also sought to enhance cooperation between the CPS agency and community partners. In one district, for example, a team of caseworkers and police officers who are co-located in a local agency respond jointly to reports of criminal abuse or neglect. In another district, nurses from the public health department, not CPS workers, take responsibility for the oversight of families with substance-exposed newborns. CPS is brought in only if additional issues of abuse and neglect arise in these families.

The district encompassing the city of Jacksonville draws on informal sources of support identified by families, such as friends or neighbors. Once an individual is identified as a potential source of support, a "community safety agreement" is developed that details what the person will do to support the family and under what circumstances the person will recontact the CPS agency. For instance, housing managers have agreed to keep an eye on families, and a minister's wife visited a neighboring family twice a day to make sure that the child was up and ready for school in the morning and fed and doing homework at night. Although hard data are not yet available on how these community safety agreements are working out in practice, anecdotal evidence is encouraging. ${ }^{27}$

The Florida reforms have drawn national attention; Missouri, South Carolina, and Virginia are moving forward with similar reforms. Although the evidence on the Florida reforms is not all in, the one completed evaluation found greater family satisfaction, more community partners involved in cases of abuse and neglect, and better safety outcomes for children in the districts that were implementing the new differential response model. ${ }^{29}$

The reformers in Florida have encountered difficulties. One problem has been resistance to reform within CPS from staff who suspected that this latest wave of reforms might be temporary-just another swing of the pendulum. Some staff feared that they would be blamed if a child died 
under the new system. ${ }^{27}$ It has also been difficult to involve community groups as partners, particularly without new funds to buy their services. In some communities, churches and others are willing to help but are hard-pressed to do so. Prospective community partners report that they, like CPS staff, are fearful about their liability in the event that a child dies or is seriously injured. ${ }^{27}$ If CPS shares responsibility for child protection with community partners, does it also share accountability when things go wrong? Or will community partners be left to face the public on their own? These questions go to the heart of the reforms, and they will continue to confront reformers in Florida and other states as changes are implemented.

\section{lowa: A Neighborhood-Based Approach}

The Patch Project in Linn County, Iowa, in operation since 1991, represents another approach to reforming child protection. ${ }^{30}$ This initiative seeks to resolve the problems of service orientation and service delivery by using a neighborhood-based interagency team to deliver child protective services and other child and family services to families at risk of abuse or neglect. Although not a legislatively mandated CPS reform like those discussed above, the Patch Project transforms the operations of the child protective services system in important ways.

The "patch" approach and name are taken from a model in Britain that assigns staff to cover specific "patches" or neighborhoods, as members of neighborhood-based interagency teams. ${ }^{3}$ The primary goals of patchworking, as it is called in Britain, are to remove barriers to service integration and to deliver services at the neighborhood level by linking CPS workers to formal and informal resources that might help children and families. Patchworking is also thought to help caseworkers gain more understanding of the culture and values held by families from racial or ethnic minority groups.

In Iowa, the reform project was implemented in a poor, inner-city Cedar Rapids neighborhood of just under 10,000 residents, where nearly half the children live in single-parent families and the rate of foster care placement is four times the statewide average of 4.6 children per $1,000 .{ }^{30}$ Prior to the reform, the area was served by a downtown Cedar Rapids office of Iowa's child protective services agency. Under the Patch Project, four CPS workers were assigned to a local office, where they joined a neighborhood-based team that included a juvenile probation officer, a city housing inspector, a county homemaker (who provides in-home help with cleaning and personal care), staff from a local community center, welfare workers, and others.

The four CPS workers handle all the CPS cases in the neighborhood, involving other members of the team on an "as needed" basis. If one social worker is out of the office, one of the other team members can step in 
to respond to a client's needs. Team members also bring CPS caseworkers into contact with families who have not been officially reported for abuse or neglect so CPS can act more proactively to prevent maltreatment from occurring.

What are the results of the Patch Project thus far? According to an evaluation by the University of Iowa, ${ }^{30}$ the CPS workers assigned to the Patch Project have developed closer working relationships with both colleagues and clients. Clients sometimes drop in to the neighborhood office, which was virtually unheard of when the CPS workers were stationed downtown. For their part, social

\section{Reformers will have to devise new ways to track accountability. Child protection is a very high-risk business, and society's demands of the child protection system are high as well.}

workers report spending more time in their clients' homes, seeing their clients informally in the neighborhood, and feeling more able to draw upon informal neighborhood resources for help. The CPS workers reported that they now define family problems differently, giving more attention to such underlying problems as poverty, inadequate housing, mental illness, unemployment, and substance abuse. The way these problems contribute to abuse or neglect has become more salient to the Patch Project caseworkers since they began assessing client needs and developing customized service plans, rather than just identifying abuse or neglect.

Implementation has not been problemfree. For example, when caseworkers are involved with families who are not identified CPS cases, administrative issues arise of how to count their activity for caseload credit. The supervision of workers stationed far from the main CPS office has also proved challenging

Overall, the patch model has been viewed as promising. The reform initiative is expanding to five additional sites in Iowa, and national interest in the model has led Oregon, Pennsylvania, and Vermont to move forward with patch initiatives of their own. These initiatives will provide valuable information about the extent to which this model can work well in more diverse settings.

\section{Challenges of Reform}

The new community-based partnership for child protection goes a long way toward addressing the five problems facing CPS that were discussed earlier. This approach would narrow the scope of the authoritative CPS system to address the overinclusion and capacity problems. It would address the underinclusion problem by developing alternative systems that use the community's formal and informal resources to serve the families no longer included in the narrowed CPS. The new paradigm's emphasis on collaborative service delivery and the involvement of informal helpers offers a solution to the service delivery problem; its emphasis on differential response addresses the service orientation problem.

There are risks and challenges associated with moving forward to a community-based approach to child protection. Some of these derive from the fact that the reach of the CPS system would be narrower, while others reflect the increased reliance on community partners and on caseworker discretion.

Narrowing the scope of CPS inevitably creates the risk that more cases of child abuse or neglect, some of them serious, will be missed. To reduce this risk, the community partnership approach would continually reassess families and spell out explicit procedures for moving cases from the voluntary track to the authoritative track. Introducing the reforms incrementally is also prudent. Missouri, for instance, piloted its dual response in just five areas. Florida began assigning cases of substance-exposed newborns to public health nurses instead of CPS caseworkers in only one community, and did so only after extensive discussions to spell out exactly which types of substance-abuse cases would be handled in this new way.

A second risk associated with narrowing CPS is that the service problems of the current CPS system will not be resolved. The cases retained in CPS could still receive a one-size-fits-all investigative response, and those cases excluded might receive no services, or services that are fragmented and 
uncoordinated. The reliance on community partnerships, the use of interagency teams, and the differential response to cases within and outside of CPS are intended to address these problems, but working in this way poses additional challenges for administrators and front-line staff.

Administrators will be called on to give front-line staff access to services that cross agency lines so that they can address the range of problems that place children at risk of abuse and neglect. How to accomplish such coordination, in a child and family services system that is fragmented and categorical, is a thorny problem. For community partnerships to function as envisioned, reformers will have to develop mechanisms for making service funding flexible, as was the case in Iowa, where the Patch Project team could take advantage of earlier reforms that had to some extent already decategorized funding.

The new paradigm also creates a larger role for informal helpers in the protection of children, but establishing links with these informal sources of support will be difficult for CPS agencies. Organized groups of informal helpers such as tenant associations or churches may be disinclined to establish formal working relationships with CPS, since some residents of low-income communities view the system with distrust and hostility. Nor will such relationships come naturally to CPS staff, many of whom do not know how to engage community resources as equal partners. Moreover, informal sources of support (such as godparents, aunts, ministers, and neighbors) vary case by case, so frontline workers and families will have to work together to identify and pull together these resources. This represents a tremendous change in the way caseworkers think about working with families.

As noted earlier, the focus on differential response that is fundamental to the new paradigm will give caseworkers more discretion to decide, for instance, whether a family can be worked with on a voluntary basis, or to determine how to involve individuals in the family's network and community. Caseworkers may have to work in new ways as they become involved with families without opening official CPS cases, and when they are based far away from their official supervisors and managers. To make sure that caseworkers are capable of exercising these new responsibilities, agencies undertaking reform will have to provide more staff training, upgrade caseworker job requirements and pay scales, and consider reducing caseloads (which often exceed 20 cases per worker).

Reformers will also have to devise new ways to track accountability. Child protection is a very high-risk business, and society's demands of the child protection system are high as well. The public wants children reliably protected from abuse and neglect and is willing to vest the system with a good deal of authority to accomplish this, but it is important that this authority not be abused or treated lightly. To provide accountability,

\section{To make sure that caseworkers are capable of exercising these new responsibilities, agencies undertaking reform will have to provide more staff training, upgrade caseworker job requirements and pay scales, and consider reducing caseloads.}

administrators can use such tools as management information systems, random case record reviews, and surveys of client satisfaction to monitor outcomes for children and families by caseworker, supervisor, and agency. When these systems produce feedback in a timely manner, workers, supervisors, and agency heads know they will be held accountable; and if something is going wrong, it can be remedied before too much damage is done.

\section{Conclusion}

The cases of Missouri, Florida, and Iowa provide three examples of how states are beginning to move toward a new paradigm for child protection-in which community partnerships comprised of CPS and other formal and informal partners together provide a differential response for families at risk of abuse or neglect. The challenges involved in getting from here to there-at the system level and at the level of the frontline worker-are substantial, but so too is the potential for making real improvements in a system that desperately needs reform. 
The initial flurry of narrowing proposals laid the groundwork for this wave of reform by emphasizing the need to narrow the scope of authoritative CPS intervention. The new paradigm described in this article articulates a fuller vision of an approach for handling those cases excluded from CPS as well as those remaining in CPS and spells out some of the steps that legislators, CPS agencies, community partners, and frontline caseworkers can take to get from here to there.

1. Gil, D. Violence against children: Physical child abuse in the United States. Cambridge, MA: Harvard University Press, 1970.

2. Wiese, D., and Daro, D. Current trends in child abuse reporting and fatalities: The results of the 1994 annual fifty-state survey. Working paper no. 808. Chicago: National Committee to Prevent Child Abuse, 1995; see also U.S. Department of Health and Human Services, National Center on Child Abuse and Neglect. Child maltreatment 1995: Reports from the states to the national child abuse and neglect data system. Washington, DC: U.S. Government Printing Office, 1997.

3. Waldfogel, J. The future of child protection. Cambridge, MA: Harvard University Press, Fall 1998.

4. Myers, J.B., ed. The backlash: Child protection under fire. Thousand Oaks, CA: Sage, 1994.

5. Besharov, D. Gaining control over child abuse reports. Public Welfare (Spring 1990) 48,2:34-40; Besharov, D. Protecting children from abuse and neglect: Policy and practice. Springfield, IL: Charles C. Thomas, 1988; Besharov, D. "Doing something" about child abuse: The need to narrow the grounds for state intervention. Harvard Journal of Law and Public Policy (1985) 8,3:539-89.

6. Farrow, F. Protecting children while supporting and preserving families. Issue paper by the Center for the Study of Social Policy, Washington, DC, 1993.

7. Kamerman, S., and Kahn, A. Social services for children, youth, and families in the United States. Children and Youth Services Review (1990) 12,1/2:1-184; Kamerman, S., and Kahn, A. If CPS is driving child welfare-Where do we go from here? Public Welfare (Winter 1990) 48,1:9-13.

8. National Association of Public Child Welfare Administrators. Guidelines for a model system of protective services for abused and neglected children and their families. Washington, DC: NAPCWA, 1988.

9. American Public Welfare Association. A commitment to change: Report of the National Commission on Child Welfare and Family Preservation. Washington, DC: APWA, 1991.

10. U.S. Advisory Board on Child Abuse and Neglect. Neighbors helping neighbors: A new national strategy for the protection of children. Washington, DC: U.S. Government Printing Office, 1993; U.S. Advisory Board on Child Abuse and Neglect. Creating caring communities: Blueprint for an effective federal policy on child abuse and neglect. Washington, DC: U.S. Government Printing Office, 1991; U.S. Advisory Board on Child Abuse and Neglect. Child abuse and neglect: Critical first steps in response to a national emergency. Washington, DC: U.S. Government Printing Office, 1990.

11. The executive session was funded by the Annie E. Casey and Edna McConnell Clark Foundations. The author is also grateful to the conveners of the session-Frank Hartmann, Mark Moore, Stewart Wakeling, and Julie Wilson—and all the participants for many helpful discussions. However, the opinions expressed here, while drawing on the executive session discussions, should not be taken as representing the views of the executive session funders or members.

12. In fact, the U.S. Advisory Board on Child Abuse and Neglect declared that CPS was in a state of emergency. See note no. 10, U.S. Advisory Board on Child Abuse and Neglect, 1990, p. 2.

13. See, for instance, Kamerman, S., and Kahn, A. Integrating services integration: An overview of initiatives, issues, and possibilities. New York: National Center for Children in Poverty, 1992; and Waldfogel, J. The new wave of service integration. Social Service Review (1997) 71,3:463-84.

14. See note no. 5, Besharov, 1990.

15. See, for instance, Lindsey, D. The welfare of children. Oxford: Oxford University Press, 1994; Pelton, L. For reasons of poverty: A critical analysis of the public child welfare system in the United States. New York: Praeger, 1989.

16. See note no. 10, U.S. Advisory Board on Child Abuse and Neglect, 1991 and 1993.

17. Child Welfare League of America. Child protection: It's everybody's business. Mimeograph. Washington, DC: CWLA, 1996. 
18. Costin, L.B., Karger, H.J., and Stoesz, D. The politics of child abuse and neglect in America. New York: Oxford University Press, 1996.

19. The documents produced for the Executive Session on Child Protection are available as working papers from the Malcolm Wiener Center for Social Policy, Kennedy School of Government, Harvard University, 79 John F. Kennedy Street, Cambridge, MA 02138.

20. Farrow, F., with the Executive Session on Child Protection. Child protection: Building community partnerships. Paper prepared for the Executive Session on Child Protection. Cambridge, MA: Kennedy School of Government, 1997. Available from the Malcolm Wiener Center for Social Policy, Kennedy School of Government, Harvard University, 79 John F. Kennedy Street, Cambridge, MA 02138.

21. Gardner, S., and Young, N. Alcohol and drug treatment: An essential ingredient in community partnerships for child protection. Paper prepared for the Executive Session on Child Protection. Cambridge, MA: Kennedy School of Government, 1997. Available from the Malcolm Wiener Center for Social Policy, Kennedy School of Government, Harvard University, 79 John F. Kennedy Street, Cambridge, MA 02138.

22. Natural helpers are individuals in the neighborhood who look out for children and help parents when they are stressed. For a discussion of the role of informal support in child protection, see Thompson, R. Preventing maltreatment through social support: A critical analysis. Thousand Oaks, CA: Sage, 1995.

23. Examples of efforts to involve informal helpers include community safety agreements, which have been used experimentally in Florida, and the family group conference model, in which family, extended family, and community members join CPS and other formal providers to develop a plan for keeping children safe. See note no. 3, Waldfogel.

24. Burrell, K. Missouri's child protective services system and current differential response demonstration project. Case study prepared for the Executive Session on Child Protection, Kennedy School of Government, Cambridge, MA, 1995. Available from the Malcolm Wiener Center for Social Policy, Kennedy School of Government, Harvard University, 79 John F. Kennedy Street, Cambridge, MA 02138.

25. See note no. 24, Burrell, p. 19.

26. Typically, Central Registries serve two purposes. A Central Registry can be used in CPS screening to check whether a child reported to CPS has been the subject of prior reports. It can also be used for employment screening to check whether an adult seeking employment in a childrelated occupation has been a perpetrator of abuse or neglect.

27. Wakeling, S. Child protective services reform in Florida: A brief update. Sequel to a case study prepared for the Executive Session on Child Protection. Kennedy School of Government, Cambridge, MA, 1996. Available from the Malcolm Wiener Center for Social Policy, Kennedy School of Government, Harvard University, 79 John F. Kennedy Street, Cambridge, MA 02138.

28. Wakeling, S. Child protective services reform in Florida. Case study prepared for the Executive Session on Child Protection. Kennedy School of Government, Cambridge, MA, 1995. Available from the Malcolm Wiener Center for Social Policy, Kennedy School of Government, Harvard University, 79 John F. Kennedy Street, Cambridge, MA 02138.

29. A preliminary evaluation of the Florida reforms was completed in December 1996. See Hernandez, M., and Barrett, B.A. Executive summary of the evaluation of Florida's Family Services Response System. Tampa, FL: University of South Florida, Florida Mental Health Institute, Department of Child and Family Studies, 1996.

30. Adams, P., Alter, C., Krauth, K., et al. Strengthening families and neighborhoods: A communitycentered approach. Final report on the Iowa Patch Project. Mimeograph. Iowa City, IA: University of Iowa, 1995. 